\title{
Seattle's minimum wage ordinance did not affect supermarket food prices by food processing category
}

\author{
Amanda L Spoden ${ }^{1}$, James H Buszkiewicz ${ }^{2}$, Adam Drewnowski ${ }^{1,2}$, Mark C Long ${ }^{3}$ and \\ Jennifer J Otten ${ }^{1, *}$ \\ ${ }^{1}$ Nutritional Sciences Program, University of Washington, Nutritional Sciences Box 353410, 305 Raitt Hall, Seattle, \\ WA 98195, USA: ${ }^{2}$ Department of Epidemiology, University of Washington, Seattle, WA, USA: ${ }^{3}$ Evans School of \\ Public Policy and Governance, University of Washington, Seattle, WA, USA
}

Submitted 20 June 2017: Final revision received 27 0ctober 2017: Accepted 6 December 2017: First published online 7 February 2018

\begin{abstract}
Objective: To examine the impacts of Seattle's minimum wage ordinance on food prices by food processing category.

Design: Supermarket food prices were collected for 106 items using a University of Washington Center for Public Health Nutrition market basket at affected and unaffected supermarket chain stores at three times: March 2015 (1-month pre-policy enactment), May 2015 (1-month post-policy enactment) and May 2016 (1-year post-policy enactment). Food items were categorized into four food processing groups, from minimally to ultra-processed. Data were analysed across time using a multilevel, linear difference-in-differences model at the store and price level stratified by level of food processing.

Setting: Six large supermarket chain stores located in Seattle ('intervention') affected by the policy and six same-chain but unaffected stores in King County ('control'), Washington, USA.

Subjects: One hundred and six food and beverage items.

Results: The largest change in average price by food item was + \$US 0.53 for 'processed foods' in King County between 1-month post-policy and 1-year postpolicy enactment $(P<0 \cdot 01)$. The smallest change was \$US 0.00 for 'unprocessed or minimally processed foods' in Seattle between 1-month post-policy and 1-year post-policy enactment $(P=0.94)$. No significant changes in averaged chain prices were observed across food processing level strata in Seattle $v$. King County stores at 1-month or 1-year post-policy enactment.

Conclusions: Supermarket food prices do not appear to be differentially impacted by Seattle's minimum wage ordinance by level of the food's processing. These results suggest that the early implementation of a city-level minimum wage policy does not alter supermarket food prices by level of food processing.
\end{abstract}

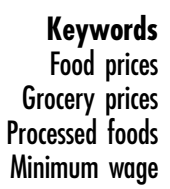

Effective 1 April 2015, the City of Seattle enacted its multistep $\$ 15$ minimum wage ordinance (MWO) to incrementally increase workers' minimum wage to \$US $15 / \mathrm{h}$ between 2017 and 2021, depending on the size of the employer and whether the employer offers medical benefits $^{(1)}$. Many municipalities in the USA are implementing similar policy measures in an attempt to address income inequality and to provide low-income workers with a living wage ${ }^{(2-6)}$

One counterargument to raising minimum wages is grounded in the concern that while increased labour wages may benefit low-wage workers, the increase in labour wages will be offset by higher prices of basic consumer goods, particularly food, thus burdening the very workers the policy is intended to help ${ }^{(7-9)}$. Food prices are of particular concern because the food system represents the largest employer of minimum-wage workers, with nearly one-third of all low-wage workers employed in the food system ${ }^{(7)}$. In particular, highly processed foods might be expected to experience greater increases in price than less processed foods based on the assumption that they must pass through more steps in the food system and thus involve more low-wage workers $^{(10,11)}$.

The current literature is mixed regarding the passthrough effects of an increase in minimum wage on fast-food and restaurant prices. A 1994 study by Card and Krueger found that fast-food restaurant prices were 
impacted by a $16 \%$ increase in minimum wage in New Jersey and rose $4 \%$ faster than fast-food restaurant prices in unaffected Pennsylvania, suggesting a pass-through effect was a factor ${ }^{(12)}$. However, the study also found the price increase to be consistent across New Jersey fast-food restaurants despite differing initial wage rates, suggesting a pass-through effect was not the only factor influencing food prices ${ }^{(12)}$. A study by Aarsonson in 2001, which focused on the timing of changes in food prices in response to an increase in minimum wage, found that an increase in federal minimum wage passed through to restaurant food prices in the first quarter after the month of enactment, but not in prior quarters or quarters thereafter $^{(13)}$. In a subsequent 2008 study, under the observation that one-third of restaurant workers are paid the minimum wage and one-third of total costs are labour costs, Aaronson et al. found that a $10 \%$ increase in the minimum wage could result in a 0.56-1.09\% price increase in restaurants in a competitive labour market ${ }^{(14)}$. Moreover, a study which evaluated the impact of a $12 \%$ increase in minimum wage in 1992 and a 9\% increase in minimum wage in 1997 found that food prices increased by less than $1 \%$ each time. The authors concluded there was only a slight pass-through effect and that the magnitude of the minimum wage increase did not differentially affect food price increases ${ }^{(15)}$.

Other studies indicate a more robust pass-through effect. One study estimated that an increase in federal minimum wage to $\$$ US $15 / \mathrm{h}$ would cause a $4 \%$ increase in fast-food restaurant prices ${ }^{(16)}$. A study of San Jose, California's increased minimum wage in 2013 found that for every $10 \%$ increase in minimum wage rate, restaurant prices increased by $0.58 \%{ }^{(17)}$. Finally, a 2016 study looked at the impact of a $33 \%$ increase in federal minimum wage on fast-food prices of a burger, pizza and chicken, and found that a burger had the most elastic price, increasing by $3 \%$ in response to an increase in minimum wage ${ }^{(18)}$.

By contrast, little is known about the effects of increased wages on supermarket food prices. Preliminary studies on the effects of Seattle's increased minimum wage on supermarket food prices have shown no evidence of changes in supermarket food prices by market basket, supermarket chain or food group in response to the early implementation of Seattle's ordinance ${ }^{(19)}$. The present study advances these analyses by exploring the effects of Seattle's increased minimum wage on supermarket food prices by level of food processing.

Grouping foods and beverages into categories based on the extent and purpose of food processing is a relatively new concept ${ }^{(20)}$. Past and present dietary guidelines use food groups (fruits, vegetables, grains, protein, dairy) to make dietary recommendations with the goal of improving diet nutrient quality ${ }^{(21-23)}$. More recently, dietary recommendations have begun to differentiate between fresh, processed and highly processed foods. This is due to emerging research showing that highly processed foods are strongly linked to obesity, type 2 diabetes and other diet-related chronic diseases, and that, for example, processed foods account for $90 \%$ of the daily intake of added sugar in the USA ${ }^{(24-27)}$.

At the same time, diets high in energy-dense foods, many of them processed, tend to cost less than do diets high in nutrient-dense foods, such as fresh and minimally processed produce $^{(28)}$. Subsequently, low-income shoppers are more likely to buy energy-dense and more highly processed foods ${ }^{(29)}$. Thus, it is important to better understand the potential pass-through effects of increased labour wages on supermarket food prices by level of food processing to understand how it might impact low-wage workers' food purchasing behaviours and thus their health.

Studies examining the effect of price increases on shopping behaviour have shown mixed results. Several studies have found that, while small taxes or subsidies on food were unlikely to have a significant impact of overweight or obesity, sizeable increases can sway dietary patterns, particularly among low-resource populations ${ }^{(30-32)}$. A review of experimental evidence on food purchasing patterns resulting from price changes found that price changes can impact the purchase of targeted foods; however, due to substitution effects it was unclear if this would positively impact health ${ }^{(33)}$. Andreyeva et al. conducted a review of the price elasticities of 160 food items and found that away-from-home foods, soft drinks, juice and meats are the most responsive to price changes, with own elasticities ranging from -0.7 to $-0.8^{(34)}$. They observed that a $10 \%$ increase in soft drink prices could result in a reduction in consumption of $8-10 \%{ }^{(34)}$. A recent study, conducted in Brazil, found that the share of ultraprocessed food items purchased at supermarkets was $25 \%$ greater than at other food stores ${ }^{(35)}$. In addition, the authors noted that a $1 \%$ increase in the price of ultraprocessed food items resulted in a $0.59 \%$ reduction in energy acquisition at supermarkets ${ }^{(35)}$.

The purpose of the current analysis was to investigate whether the increase in minimum wage had a differential effect on supermarket food prices based on level of processing in supermarkets affected and unaffected by the MWO.

\section{Methods}

\section{Data source}

The data for the present study come from a market basket survey conducted by the Seattle Minimum Wage Study Team to evaluate the effects of Seattle's MWO on supermarket food prices ${ }^{(36)}$. The use of a market basket is a commonly used approach to assess food prices ${ }^{(37-39)}$. This approach is currently used by the US Bureau of Labor and Statistics to calculate the Consumer Price Index (CPI) as well as in other metropolitan cities such as Chicago ${ }^{(40,41)}$.

The current market basket consisted of 106 food and beverage items and was developed by the University of 
Washington's Center for Public Health Nutrition based on the CPI and Thrifty Food Plan market baskets ${ }^{(37)}$. The market basket includes common unhealthy and healthy items, including foods recommended in the Behavioral Risk Factors Surveillance System nutrition module and the 2015 Dietary Guidelines for Americans ${ }^{(21,22)}$.

\section{Data collection}

Details of the data collection are described in detail in a previously published paper and elsewhere $(18,19,42,43)$. Briefly, data were collected at six affected supermarket chain stores in Seattle and six same-chain but unaffected supermarket chain stores in King County, Washington, USA in March 2015 (baseline: 1-month pre-policy enactment), May 2015 (follow-up 1: 1-month post-policy enactment) and May 2016 (follow-up 2: 1-year post-policy enactment) to capture supermarket prices at 1-month pre-, 1 -month post- and 1-year post-MWO enactment. Table 1 shows the phase-in schedule for Seattle's minimum wage at the three time points of data collection. The six supermarket chains were selected for the study based on a prior Seattle study conducted by Drewnowski et al. in 2012, showing that $65 \%$ of a representative sample of Seattle and King County residents identified these six chains as a primary food source ${ }^{(37)}$. These supermarket chains were also selected for inclusion of low price, medium price and high price total market basket costs, as determined by a 2009 Seattle study ${ }^{(37,39)}$. These chains represent fifty of the seventy-eight supermarkets affected by the MWO in Seattle.

For each market basket item, one researcher trained in the protocol recorded the lowest price available. This was often the store brand price. If store brand price was not the cheapest or not available, the next lowest price was recorded. No sales, promotions, coupons or discounted prices were recorded. When possible, items recorded were in the same purchasable form as prior collections. Market basket item prices with variable sizes were based on medium-sized items. If an item was not found, the researcher asked a store worker to help locate it. If the item was still unavailable, a similar product was chosen. For example, if a supermarket did not have a Red Delicious apple, the price of a medium-sized Fuji apple was recorded. In the rare event a similar product was not

Table 1 Timeline of Seattle's minimum wage increase during data collection

\begin{tabular}{lll}
\hline $\begin{array}{l}\text { Date of data } \\
\text { collection }\end{array}$ & $\begin{array}{l}\text { Minimum } \\
\text { waget, }\end{array}$ & Time point \\
\hline March 2015 & \$US 9.47/h & 1-month pre-enactment \\
May 2015 & \$US 11.00/h & 1-month post-enactment \\
May 2016 & \$US 13.00/h & 1-year post-enactment \\
\hline
\end{tabular}

†For large employers who do not pay towards an employee's medical benefits $^{(1)}$.

$\ddagger$ Three other phase-in schedules are possible based on employer size and provision of employee benefits. For more information, please visit: https:// www.seattle.gov/laborstandards/ordinances/minimum-wage/. available, the researcher left that item price null and documented the attempt to locate it.

\section{Food processing categorization}

For the current analysis, market basket food items were categorized by level of food processing or the degree to which natural food was altered to create food products. Food processing categorization was assigned based on the extent of food processing and was determined using a food classification system commonly used by other studies $^{(24,39,44,45)}$. Based on the food classification system used by Martínez Steele et al., food processing categories, detailed in Table 2, included: unprocessed or minimally processed foods (group 1), processed culinary ingredients (group 2), processed foods (group 3) and ultra-processed foods (group 4) ${ }^{(24)}$.

Market basket items were independently coded by two researchers for data verification purposes. Researchers agreed upon the food processing categorization of ninetythree ( $88 \%$ ) of the 106 market basket items. The remaining thirteen (12\%) items were decided and agreed upon using a third researcher.

\section{Statistical analysis}

For the present study, all prices were converted to itemstandardized units. For example, all prices collected for canned green beans were standardized to represent the price of a $411 \mathrm{~g}(14.5 \mathrm{oz})$ can, the most commonly available item unit. The 'total market basket price' is the sum of

Table 2 Food processing categorization based on the level of processing

\begin{tabular}{|c|c|c|}
\hline $\begin{array}{l}\text { Food processing } \\
\text { category }\end{array}$ & Defined as & $\begin{array}{l}\text { Market basket } \\
\text { examples }\end{array}$ \\
\hline $\begin{array}{l}\text { Group 1: } \\
\text { unprocessed or } \\
\text { minimally } \\
\text { processed } \\
\text { foods }\end{array}$ & $\begin{array}{l}\text { Foods taken directly } \\
\text { from nature; } \\
\text { minimally processed } \\
\text { to clean, pasteurize, } \\
\text { freeze, or other } \\
\text { processes that do } \\
\text { not alter the } \\
\text { composition }\end{array}$ & $\begin{array}{l}\text { Coffee, rice, milk, } \\
\text { apples, frozen } \\
\text { turkey, broccoli } \\
\text { (n 60) }\end{array}$ \\
\hline $\begin{array}{l}\text { Group 2: } \\
\text { processed } \\
\text { culinary } \\
\text { ingredients }\end{array}$ & $\begin{array}{l}\text { Ingredients that can be } \\
\text { added to group } 1 \text { for } \\
\text { flavour or seasoning } \\
\text { used in the cooking } \\
\text { process }\end{array}$ & $\begin{array}{l}\text { Flour, butter, } \\
\text { shortening, sugar } \\
(\text { ( } 7)\end{array}$ \\
\hline $\begin{array}{l}\text { Group 3: } \\
\text { processed } \\
\text { foods }\end{array}$ & $\begin{array}{l}\text { Foods from group } 1 \\
\text { that are minimally } \\
\text { processed, often } \\
\text { with salt or oil, with } \\
\text { the intent of } \\
\text { extending shelf-life } \\
\text { or altering } \\
\text { palatability; includes } \\
\text { fermented alcoholic } \\
\text { beverages }\end{array}$ & $\begin{array}{l}\text { Tortillas, tofu, canned } \\
\text { salmon, canned } \\
\text { corn, wine }(n 12)\end{array}$ \\
\hline $\begin{array}{l}\text { Group 4: ultra- } \\
\text { processed } \\
\text { foods }\end{array}$ & $\begin{array}{l}\text { Foods that are highly } \\
\text { processed with the } \\
\text { intent of } \\
\text { convenience and } \\
\text { ready-to-eat/drink }\end{array}$ & $\begin{array}{l}\text { Cookies, ice cream, } \\
\text { salad dressing, } \\
\text { sausages, cola, } \\
\text { potato chips }(n 27)\end{array}$ \\
\hline
\end{tabular}


the market basket food items per location. The 'average market basket price per food processing category' is the mean price of the market basket food processing category per location.

A complete case analysis was conducted to exclude any item that was not consistent over the three data collection time points. Unpaired $t$ tests were used to detect price differences by location at a fixed time. Paired $t$ tests were used to detect average price differences, by food processing group and location, across time. A multilevel, linear difference-in-differences model was used to identify changes in the average market basket item food prices attributable to the MWO:

$$
\begin{aligned}
\text { Price }_{i j k t}= & \alpha_{j}+\beta_{k} \text { Seattle }_{k}+\gamma_{1} \text { Post }_{t}+\gamma_{2} \text { Post }_{t} \\
& +\delta_{1} \text { Post }_{t} \times \text { Seattle }_{k}+\delta_{2} \text { Post }_{t} \times \text { Seattle }_{k}+\varepsilon_{i j k t},
\end{aligned}
$$

where Price $_{i j k t}$ is the estimated mean price for a food item $i$ at store $j$ in region $k$ (affected (Seattle) or unaffected (King County) stores) at time $t . \alpha_{j}$ is a store-level random effect. Seattle $_{k}$ is an indicator that equals 1 for Seattle stores and 0 for King County stores, and $\beta_{k}$ captures differences in mean item-level prices across regions. Post $1_{t}$ are Post $2_{t}$ are indicator variables that equal 1 for prices measured in the first (1-month or May 2015) and second follow-up periods (1-year or May 2016), respectively, and $\gamma_{1}$ and $\gamma_{2}$ capture differences in mean item-level prices across time relative to the baseline period.

Post $_{t} \times$ Seattle $_{k}$ and Post ${ }_{t} \times$ Seattle $_{k}$ equal 1 only for Seattle stores in the follow-up periods 1 and 2 , and $\delta_{1}$ and $\delta_{2}$ capture the difference in prices in Seattle in the postpolicy periods that cannot be explained by region and time effects, and thus appear to be attributable to the MWO in each period. $\varepsilon_{i j k t}$ is the idiosyncratic error. In addition, this model utilized robust standard errors clustered at the store level.

Overall, there were twenty-one (2\%) market basket items out of 1272 items missing from follow-up 2 data collection. Missing data were assumed to be missing at random. A complete case statistical analysis was conducted, dropping missing items which did not have a comparison by time or within store. Missing items were dropped between baseline and follow-up 2 ( $n$ 12) and follow-up 1 and follow-up 2 ( $n$ 10). No items were missing between baseline and follow-up 1 .

\section{Results}

Table 3 shows the range of differences in average market basket price per food processing category between Seattle and King County at each time point. Negative price differences indicate King County had higher prices and positive price differences indicate Seattle had higher prices, on average, per food processing category. At baseline, follow-up 1 and follow-up 2, unprocessed or minimally processed foods (group 1) had the largest difference in prices between Seattle and King County.

Figure 1 shows the sum of market basket item prices within each food processing category by store chain and location at baseline, follow-up 1 and follow-up 2. There were no statistically significant differences in average prices between locations or supermarket chains at baseline, follow-up 1 or follow-up 2 for any food processing category.

Figure 2 illustrates the change in average price per item by food processing category by location between time points. The largest change in the average item market basket price between baseline and follow-up 1 was - \$US 0.13 for processed foods (group 3) in Seattle; between follow-up 1 and follow-up 2 was \$US 0.53 for processed culinary ingredients (group 2) in King County; and between baseline and follow-up 2 was \$US 0.46 for processed culinary ingredients (group 2) in Seattle. The smallest change in the average item market basket price between baseline and follow-up 1 and baseline and follow-up 2 was - \$US 0.01 for unprocessed or minimally processed foods (group 1) in Seattle; and between followup 1 and follow-up 2 was \$US 0.00 for unprocessed or minimally processed foods (group 1) in Seattle.

There was a statistically significant change in the average price per item for processed culinary ingredients (group 2) in both Seattle and King County between

Table 3 The range in differences and mean differences in the average market basket price between Seattle ('intervention') and King County

\begin{tabular}{|c|c|c|c|c|c|c|}
\hline \multirow[b]{2}{*}{ Food processing category } & \multicolumn{2}{|c|}{ Baseline } & \multicolumn{2}{|c|}{ Follow-up 1} & \multicolumn{2}{|c|}{ Follow-up 2} \\
\hline & $\begin{array}{c}\text { Range in price } \\
\text { differences } \\
\text { (\$US) } \dagger\end{array}$ & $\begin{array}{c}\text { Mean } \\
\text { difference } \\
(\$ \cup S)\end{array}$ & $\begin{array}{c}\text { Range in price } \\
\text { differences } \\
\text { (\$US)† }\end{array}$ & $\begin{array}{c}\text { Mean } \\
\text { difference } \\
(\$ \cup S)\end{array}$ & $\begin{array}{l}\text { Range in price } \\
\text { differences } \\
\text { (\$US) } \dagger\end{array}$ & $\begin{array}{c}\text { Mean } \\
\text { difference } \\
(\$ \cup S)\end{array}$ \\
\hline $\begin{array}{l}\text { Group 1: unprocessed or minimally } \\
\text { processed foods }\end{array}$ & -1.77 to 6.73 & 1.97 & -7.07 to 2.10 & $1 \cdot 86$ & $-2 \cdot 74$ to 10.56 & $4 \cdot 88$ \\
\hline Group 2: processed culinary ingredients & -1.71 to $2 \cdot 10$ & -0.27 & -0.01 to .96 & $1 \cdot 10$ & -1.34 to 0.49 & $-0 \cdot 16$ \\
\hline Group 3: processed foods & -0.81 to 3.38 & 1.48 & -1.39 to 4.44 & 1.41 & -1.73 to 0.00 & -0.63 \\
\hline Group 4: ultra-processed foods & -4.09 to 4.23 & -0.43 & -2.64 to 4.96 & 1.41 & -6.31 to 3.87 & -0.47 \\
\hline
\end{tabular}
('control'), by food processing category, following Seattle's minimum wage ordinance

Baseline, March 2015 (1-month pre-policy enactment); follow-up 1, May 2015 (1-month post-policy enactment); follow-up 2, May 2016 (1-year post-policy enactment).

†Differences between prices were computed by subtracting the price of each food processing category (the sum of individual item prices within each category) in King County from the price of the same food processing category in the corresponding Seattle supermarket chain. 

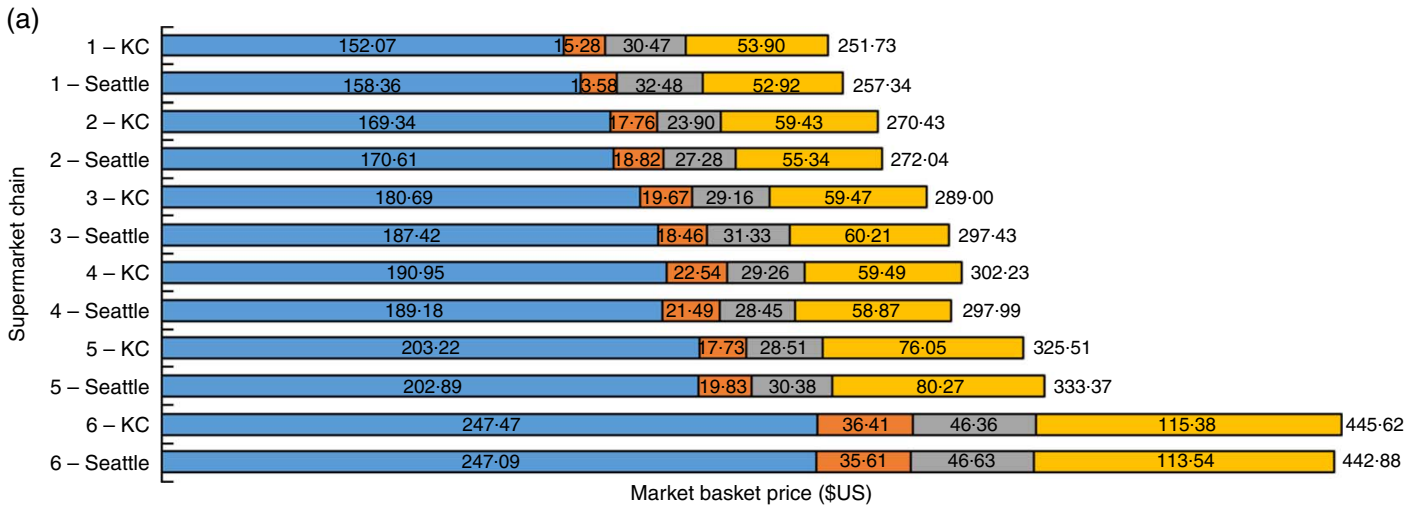

(b)
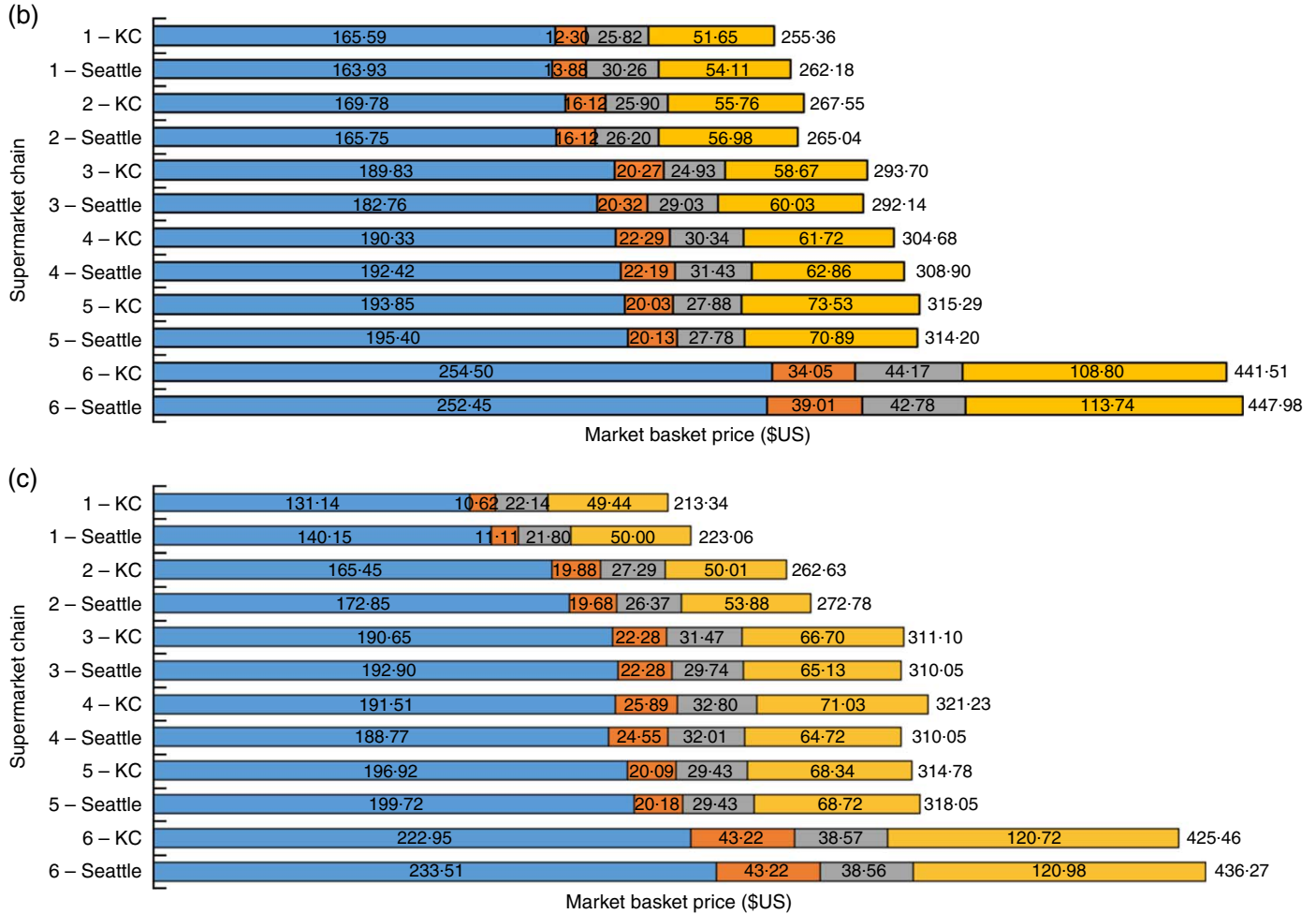

Fig. 1 (colour online) Impact of Seattle's minimum wage ordinance on supermarket food prices. Market basket item prices summed within food processing category ( $\square$, group 1: unprocessed or minimally processed foods; $\square$, group 2: processed culinary ingredients; $\square$, group 3: processed foods; $\square$, group 4: ultra-processed foods), by store chain (1-6) and location (Seattle, 'intervention'; King County (KC), 'control') at (a) baseline (March 2015; 1-month pre-policy enactment), (b) follow-up 1 (May 2015 ; 1-month post-policy enactment) and (c) follow-up 2 (May 2016; 1-year post-policy enactment)

follow-up 1 and follow-up 2 and between baseline and follow-up $2(P<0 \cdot 01)$; and for unprocessed or minimally processed foods (group 1) in King County between follow-up 1 and follow-up $2(P=0 \cdot 04)$.

Table 4 shows the results of the multilevel, differencein-differences model. There is no evidence, either overall or for any specific food group, that the Seattle MWO raised supermarket prices. No change in average price per item in Seattle reached statistical significance for any of the food processing groups for follow-up 1 (1-month post-policy enactment) or follow-up 2 (1-year post-policy enactment). The largest estimated price change in Seattle that could be attributed to the MWO was \$US $0 \cdot 20$ ( $\mathrm{SE}=\$ \mathrm{US} 0 \cdot 16$ ) for processed culinary ingredients (group 2) between baseline and follow-up 1. Further note that the estimated impacts are \$US 0.00 for both unprocessed or minimally processed foods (group 1) and ultra-processed foods (group 4) between baseline and follow-up 2 ( $\mathrm{SE}=$ \$US 0.06 and $0 \cdot 16$, respectively).

\section{Discussion}

The present study examined the effect of Seattle's MWO on supermarket food prices by level of food processing as the policy was being implemented and phased in from \$US $9 \cdot 47 / \mathrm{h}$ to $\$$ US $11 \cdot 00 / \mathrm{h}$ to $\$$ US $13 \cdot 00 / \mathrm{h}$. Results indicate 
(a)

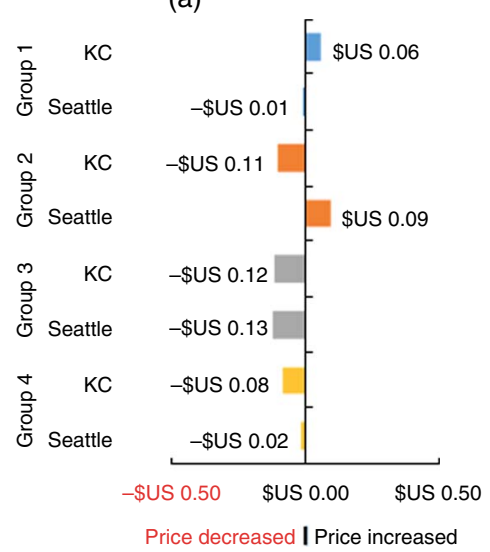

(b)

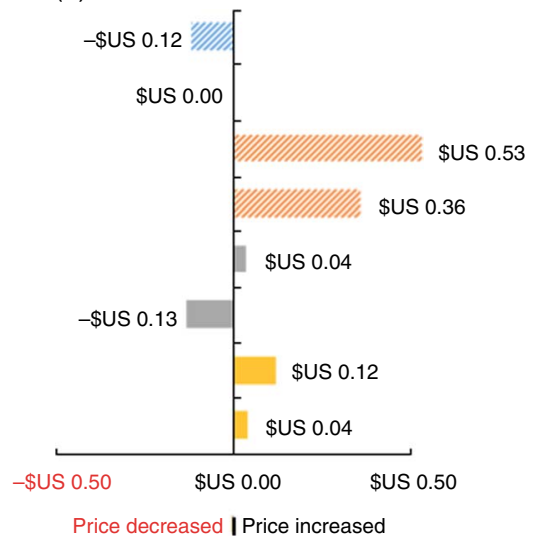

(c)

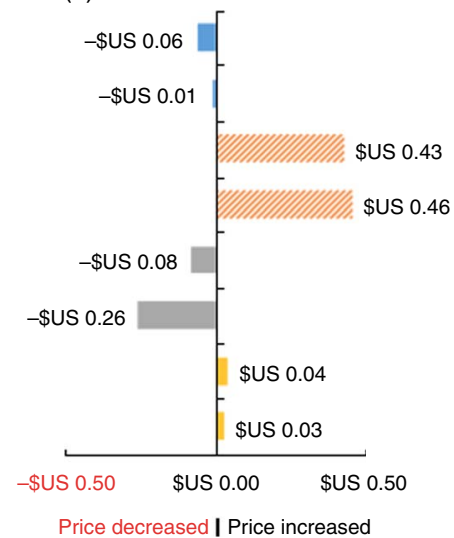

Fig. 2 (colour online) Impact of Seattle's minimum wage ordinance on supermarket food prices. Change† in average price of market basket food items by food processing category ( $\square$, group 1: unprocessed or minimally processed foods; $\square$, group 2: processed culinary ingredients; $\square$, group 3: processed foods; $\square$, group 4: ultra-processed foods) in Seattle ('intervention') and King County (KC; 'control') between (a) baseline (March 2015; 1-month pre-policy enactment) and follow-up 1 (May 2015; 1-month post-policy enactment), (b) follow-up 1 and follow-up 2 (May 2016; 1-year post-policy enactment) and (c) baseline and follow-up $2 \ddagger$. †Change was computed by subtracting baseline from follow-up 1, follow-up 1 from follow-up 2, and baseline from follow-up 2; łpaired $t$ tests were used to detect differences across time, statistically significant changes indicated by diagonal hatching

Table 4 Overall and food processing group-stratified generalized least-squares regression results for the mean change in item-level price across Seattle ('intervention') and King County ('control') stores and time, from March 2015 to May 2016, following Seattle's minimum wage ordinance

\begin{tabular}{|c|c|c|c|c|c|}
\hline \multirow[b]{2}{*}{ Mean difference in price estimates } & \multirow[b]{2}{*}{ Overall } & \multicolumn{4}{|c|}{ Food processing group } \\
\hline & & $\begin{array}{l}\text { Group 1: unprocessed } \\
\text { or minimally } \\
\text { processed foods }\end{array}$ & $\begin{array}{l}\text { Group 2: processed } \\
\text { culinary } \\
\text { ingredients }\end{array}$ & $\begin{array}{l}\text { Group 3: } \\
\text { processed } \\
\text { foods }\end{array}$ & $\begin{array}{l}\text { Group 4: ultra- } \\
\text { processed } \\
\text { foods }\end{array}$ \\
\hline \multicolumn{6}{|l|}{ Seattle (relative to King County) } \\
\hline Mean (\$US) & 0.03 & 0.03 & -0.04 & $0 \cdot 12$ & -0.02 \\
\hline SE (\$US) & 0.35 & 0.29 & 0.57 & 0.34 & 0.48 \\
\hline \multicolumn{6}{|l|}{ Follow-up 1 (relative to baseline period) } \\
\hline Mean (\$US) & -0.01 & 0.06 & -0.11 & -0.12 & $-0.08^{*}$ \\
\hline SE (\$US) & 0.02 & 0.05 & 0.12 & 0.09 & 0.04 \\
\hline \multicolumn{6}{|l|}{ Follow-up 2 (relative to baseline period) } \\
\hline Mean (\$US) & 0.00 & -0.05 & $0.43^{\star \star \star}$ & -0.08 & 0.03 \\
\hline SE (\$US) & 0.06 & 0.04 & 0.12 & 0.18 & $0 \cdot 12$ \\
\hline \multicolumn{6}{|l|}{ Seattle $\times$ Follow-up 1} \\
\hline Mean (\$US) & -0.01 & -0.06 & 0.20 & -0.01 & 0.07 \\
\hline SE (\$US) & 0.05 & 0.07 & $0 \cdot 16$ & 0.12 & 0.08 \\
\hline \multicolumn{6}{|l|}{ Seattle $\times$ Follow-up 2} \\
\hline Mean (\$US) & -0.02 & 0.00 & -0.04 & -0.18 & 0.00 \\
\hline SE (\$US) & 0.08 & 0.06 & 0.20 & 0.25 & 0.16 \\
\hline Observations $(n)$ & 3776 & 2128 & 245 & 432 & 971 \\
\hline Stores $(n)$ & 12 & 12 & 12 & 12 & 12 \\
\hline$R^{2}$ within & 0.0000123 & 0.00017 & 0.01110 & 0.00247 & 0.00050 \\
\hline$R^{2}$ between & 0.000185 & 0.00006 & 0.03340 & 0.00452 & 0.00028 \\
\hline$R^{2}$ overall & 0.0000221 & 0.00015 & 0.00888 & 0.00262 & 0.00042 \\
\hline
\end{tabular}

Baseline, March 2015 (1-month pre-policy enactment); follow-up 1, May 2015 (1-month post-policy enactment); follow-up 2, May 2016 (1-year post-policy enactment).

$P$ values come from Wald tests.

${ }^{\star} P<0.05,{ }^{\star \star \star} P<0.001$.

no statistically significant change in supermarket food prices by level of processing between supermarkets affected and unaffected by Seattle's MWO over time. This result suggests there was no evidence of a pass-through effect of increased labour wages at 1-year post-policy enactment on supermarket food prices by level of food processing.

Our findings are consistent with Katz and Krueger's 1992 study that found fast-food prices were not directly impacted by a $22 \%$ increase in federal minimum wage ${ }^{(46)}$ and with Card and Krueger's well-known 1994 study which found that changes in fast-food prices were not solely attributable to an increase in minimum wage ${ }^{(12)}$. However, our findings are inconsistent with a more recent study which found that an increase in federal minimum wage to $\$ \mathrm{US} 15 / \mathrm{h}$ would increase fast-food prices by $4 \%{ }^{(16)}$. To our knowledge, no prior studies have evaluated the impact of a city-wide increase 
in minimum wage on supermarket food prices by level of food processing. The present study fills this gap in the literature and serves as an initial study on which future studies can be based and compared. These findings are important in understanding the implications of the minimum wage on public health. Because low-income shoppers are more likely to purchase and consume highly processed foods rich in fat and sugar, which are linked to obesity and other diet-related chronic diseases, it is important to understand how potential pass-through effects of increased labour wages might differentially impact food prices ${ }^{(24-26,28)}$. This has important public health implications because, as noted earlier, low socioeconomic shoppers tend to be particularly price sensitive to changes in price among highly processed food items ${ }^{(34,35)}$.

There are many possible explanations for our lack of observed changes in supermarket food prices by level of food processing. First, processed foods are handled by minimum- and low-wage food system workers at both the food processing level and the retail level (in-store supermarket employees). Because food processing tends to occur outside Seattle, these labour wages would not be affected by the MWO. However, retail-level employees working in Seattle supermarkets would be impacted by the MWO and their increased wages may pass through to food prices. Given that our findings suggest that an increase in minimum wage for retail supermarket employees does not translate to an increase in supermarket food prices, these results could be explained by Seattle's low-wage workers contributing a small share to the total amount of input cost in producing these supermarket foods. Second, the percentage of supermarket employees receiving minimum wage may not be great enough to impact food prices. Using administrative earnings and hours data from over 500 grocery establishments provided by the Washington Employment Security Department, we find that $14.3 \%$ of jobs in grocery stores (NAICS (North American Industry Classification System) code 445110) in Seattle and 29.3\% in the rest of King County earned less than $\$ U S 11 / \mathrm{h}$ in the year preceding the passage of the MWO. Yet, these proportions are higher when compared with all low-wage wage jobs in all industry sectors, 7·2 and $9.9 \%$ respectively, and thus the effect of the MWO on prices should be greater in grocery stores than in other industries. Given that the supermarket industry is competitive, we might expect food prices to increase in Seattle by $0.76 \%$ in response to the initial increase to $\$ \mathrm{US} 11.00$ from \$US $9.47(14.3 \% \times 33 \% 16.2 \%)$ and $0.73 \%$ in response the increase to \$US 13.00 from \$US $11.00(14.3 \% \times 33 \% \times$ $15.4 \%$ ) based on calculations by Aaronson et al. in $2008^{(14,47,48)}$. Third, four of the six supermarket chains are unionized and the union contracts or the corporate supermarket chains may have had a higher minimum wage rate in 2015 than Seattle's \$US 9.47/h rate. Consequently, the percentage increase in Seattle's minimum wage from baseline to follow-up 2 would not be reflected in these supermarket chains. In our analysis, we did assess for differences by union status, both as a stratification variable and a covariate; no differences were found. However, given our relatively small sample, we were likely not sufficiently powered for this analysis. Fourth, highly processed foods may require fewer low-wage workers if highly processed foods are made by machines and unprocessed foods are hand-picked by workers. Fifth, there was an 11-month time gap from when Seattle's minimum wage policy was proposed to the time of enactment, such that baseline prices may have been preemptively increased to capture predicted wage increases ${ }^{(2)}$. Lastly, the duration of exposure to MWO may not be sufficient to have a lasting impact on supermarket prices.

There were many strengths of the present study. First, it is a prospective, longitudinal study that observed the impact of Seattle's incremental minimum wage increases over time at the same stores and across the same market basket items. Second, it used the established methodologies of the market basket approach and the food processing classification system. Despite these strengths, there are some limitations. First, the study is unable to capture wage or wage changes of the food workers in the food processing chain outside Washington State. Many studies have shown that the food processing chain is largely global in its scope. Second, we did not have information on prepared foods and thus we cannot comment on whether prices were passed through at the store level. Third, these results may not be generalizable to other localities. Fourth, our data do not capture purchasing habits, food and beverage item consumption, nor health outcomes. However, these data do contribute to the limited research on the effects of minimum wage policies on supermarket food prices. Fifth, the price of items collected reflected the lowest non-discounted cost of food items, which may not reflect the true cost of food items for shoppers. However, this market basket is a validated tool based on the same method the US Bureau of Labor and Statistics uses to calculate national, regional and city-level $\mathrm{CPI}^{(37,38,40,41,49,50)}$.

While not statistically significant, the present study found that unprocessed or minimally processed foods had the greatest difference in price between affected and unaffected supermarkets at all three time points. This finding, while unrelated to the increase in minimum wage, is interesting in that it suggests that supermarkets set a wider range in price for unprocessed or minimally processed foods by supermarket chain location than other processed food categories. At the same time, these items changed the least in price between time points. Future studies should examine these relationships using larger samples and greater regional variation.

\section{Conclusion}

In conclusion, the current analysis finds no evidence of a pass-through effect of increased labour wages due to a city-wide minimum wage on supermarket food prices by 
level of food processing. Future data collection is planned to capture supermarket food prices after longer durations of MWO enactment to provide further insights. Future studies should look at the impact of an increase in minimum wage on supermarket food items by price elasticity. Future research on the effects of local minimum wages on supermarket food prices should examine a larger sample of supermarket food prices, as well as greater variety of chains (e.g. national, regional and local; single-site $v$. multi-site; union $v$. non-union).

\section{Acknowledgements}

Acknowledgements: The authors thank Anju Aggarwal, Wesley Tang and the Seattle Minimum Wage Study Team for their advice and support. Financial support: The work was supported by grants from the Laura and John Arnold Foundation (http://www.arnoldfoundation.org/grants/); and the City of Seattle (grant number OCA 2014-04 AM03). The Laura and John Arnold Foundation and the City of Seattle had no role in the design, analysis or writing of this article. Conflict of interest: None. Authorship: A.L.S.: acquisition of data, interpretation of the data, drafting the manuscript, final approval; J.H.B.: analysis of data, interpretation of the data, critical revision of the manuscript, final approval; A.D.: conceptual design, revision of the manuscript, final approval; M.C.L.: revision of the manuscript, final approval; J.J.O.: conceptual design, interpretation of the data, critical revision of the manuscript, final approval. Ethics of buman subject participation: Not applicable.

\section{References}

1. Office of Labor Standards (n.d.) Information for large employers. http://www.seattle.gov/laborstandards/ordinances/mini mum-wage/large-employers (accessed February 2017).

2. Office of the Mayor (2014) Murray: 'We have a deal: Seattle workers are getting a raise'. http://www.murray.seattle.gov/ murray-we-have-a-deal-seattle-workers-are-getting-a-raise/ (accessed February 2017).

3. Office of the Mayor (2017) Mayor Murray marks milestone for Seattle's minimum wage. http://www.murray.seattle. gov/mayor-murray-marks-milestone-seattles-minimum-wage/ (accessed February 2017).

4. Missouri Jobs with Justice (n.d.) City-wide minimum wage increases hoping to lead the country by example. http:// www.mojwj.org/city-wide-minimum-wage-increases-hopingto-lead-the-countryby-example/ (accessed February 2017).

5. Los Angeles Times (2015) Los Angeles' minimum wage on track to go up to $\$ 15$ by 2020 . http://www.latimes.com/ local/lanow/la-me-ln-minimum-wage-hike-20150518-story. html (accessed February 2017).

6. Cincinnati.com (2015) Council approves $\$ 15$ wage for workers; no private mandate coming. http://www.cincin nati.com/story/money/2016/04/28/city-hall-votes-15-wage-city wide-mandatepossible/83520360 (accessed February 2017).

7. The Food Labor Research Center at the University of California Berkeley, The Food Chain Workers Alliance \& The Restaurant Opportunities Center (2012) A dime a day: the impact of the Miller/Harkin minimum wage proposal on the price of food. http://www.laborcenter.berkeley.edu/ pdf/2012/price_food12.pdf (accessed February 2017).

8. CATO Institute (n.d.) Four reasons not to raise the minimum wage. https://www.object.cato.org/sites/cato. org/files/four_reasons_not_to_raise_the_minimum_wage.pdf (accessed February 2017).

9. American Enterprise Institute (2015) Ten reasons economists object to the minimum wage. http://www.aei.org/ publication/ten-reasons-economists-object-to-the-minimumwage/ (accessed February 2017).

10. Bureau of Labor Statistics (2017) Crop Production: NAICS 111. http://www.bls.gov/iag/tgs/iag111.htm (accessed June 2017).

11. Bureau of Labor Statistics (2017) Food Manufacturing: NAICS 311. http://www.bls.gov/iag/tgs/iag311.htm" ${ }^{*}$ work force (accessed June 2017).

12. Card D \& Krueger AB (1994) Minimum wages and employment: a case study of the fast-food industry in New Jersey and Pennsylvania. Am Econ Rev 84, 772-793.

13. Aaronson D (2001) Price pass-through and the minimum wage. Rev Econ Stat 83, 158-169.

14. Aaronson D, French E \& MacDonald J (2008) The minimum wage, restaurant prices, and labor market structure. J Hum Resour 45, 688-720.

15. Lee C, Schluter GE \& O'Roark B (2003) Minimum wage and food prices: an analysis of price passthrough effects. Int Food Agribus Manag Rev 3, 111-128.

16. Ma J \& Ghiselli $R$ (2016) The minimum wage, a competitive wage, and the price of a burger: can competitive wages be offered in limited-service restaurants? J Foodserv Bus Res 19, 131-146.

17. Allegretto S \& Reich M (2018) Are local minimum wages absorbed by price increases? Estimates from internet-based restaurant menus. ILR Rev 71, 35-63.

18. Otten J, Buszkiewicz J, Tang W et al. (2017) The impact of a city-level minimum-wage policy on supermarket food prices in Seattle-King County. Int J Environ Res Public Health 14, E1039.

19. University of Washington (2016) Early evidence on the impact of Seattle's minimum wage ordinance. http://www. evans.uw.edu/sites/default/files/HOvIV\%201-27-16.pdf (accessed June 2017).

20. Monteiro CA (2009) Nutrition and health. The issue is not food, nor nutrients, so much as processing. Public Health Nutr 12, 729-731.

21. Center for Disease and Control and Prevention (n.d.) Surveillance of fruit and vegetable intake using the Behavioral Risk Factor Surveillance System. http://www.cdc.gov/brfss/ pdf/fruits_vegetables.pdf (accessed February 2017).

22. US Department of Health and Human Services \& US Department of Agriculture (2015) Dietary Guidelines for Americans 2015-2020, 8th ed. http://health.gov/diet aryguidelines/2015/guidelines/ (accessed February 2017).

23. US Department of Agriculture (2017) Choose MyPlate. http:// www.choosemyplate.gov/MyPlate (accessed February 2017).

24. Martínez Steele E, Baraldi LG, Costa Louzada ML et al. (2016) Ultra-processed foods and added sugars in the US diet: evidence from a nationally representative crosssectional study. BMJ Open 6, e009892.

25. World Health Organization (2003) Diet, Nutrition and the Prevention of Chronic Diseases. http://www.who.int/diet physicalactivity/publications/trs916/en/gsfao_introduction. pdf (accessed February 2017).

26. World Cancer Research Fund International (2007) Expert Report: Food, Nutrition, Physical Activity and the Prevention of Cancer: A Global Perspective.http://www.wcrf.org/int/ research-we-fund/continuous-update-project-cup/secondexpert-report (accessed February 2017).

27. Jannasch F, Kröger J \& Schulze MB (2017) Dietary patterns and type 2 diabetes: a systematic literature review 
and meta-analysis of prospective studies. J Nutr 147, 1174-1182.

28. Drewnowski A, Darmon N \& Briend A (2004) Replacing fats and sweets with vegetables and fruits - a question of cost. Am J Public Health 94, 1555-1559.

29. Darmon N \& Drewnowski A (2008) Does social class predict diet quality? Am J Clin Nutr 87, 1107-1117.

30. Powell L \& Chaloupka F (2009) Food prices and obesity: evidence and policy implications for taxes and subsidies. Milbank Q 87, 229-257.

31. Eyles H, Mhurchu C, Nghiem N et al. (2012) Food pricing strategies, population diets, and noncommunicable disease: a systematic review of simulation studies. PLoS Med 9, e1001353.

32. Schroeter C, Lusk J \& Tyner W (2008) Determining the impact of food price and income changes on body weight. $J$ Health Econ 27, 45-68.

33. Epstein L, Jankowiak N, Nederkoorn C et al. (2012) Experimental research on the relation between food price changes and food-purchasing patterns: a targeted review. Am J Clin Nutr 95, 789-809.

34. Andreyeva T, Long M \& Brownell K (2010) The impact of food prices on consumption: a systematic review of research on the price elasticity of demand for food. $A m J$ Public Health 100, 216-222.

35. Machado P, Claro R, Canella D et al. (2017) Price and convenience: the influence of supermarkets on consumption of ultra-processed foods and beverages in Brazil. Appetite 116, 381-388.

36. University of Washington (2016) Report on baseline employer survey and worker interviews. http://www.seat tle.gov/Documents/Departments/CityAuditor/auditreports/ FinalMinWageReport0416.pdf (accessed February 2017).

37. Drewnowski A, Aggarwal A, Hurvitz PM et al. (2012) Obesity and supermarket access: proximity or price? $A m \mathrm{~J}$ Public Health 102, e74-e80.

38. Monsivais P \& Drewnowski A (2017) The rising cost of low-energy-density foods. J Am Diet Assoc 107, 2071-2076.

39. University of Washington Center for Public Health Nutrition (2009) The search for affordable nutrient rich foods: a comparison of supermarket food prices in Seattle-King County. http://www.depts.washington.edu/uwcphn/reports/ cphnbrf2.pdf (accessed February 2017).

40. Bureau of Labor Statistics (2017) Consumer price index frequently asked questions. http://www.bls.gov/cpi/cpifaq. htm\#Question_6 (accessed February 2017).

41. Block D \& Kouba J (2006) A comparison of the availability and affordability of a market basket in two communities in the Chicago area. Public Health Nutr 9, 837-845.

42. Buszkiewicz J, Otten J, Tang W et al. (2016) The effect of a city-level minimum-wage policy on food prices: a study of supermarket food prices in Seattle-King County. Presented at AcademyHealth Annual Research Meeting, Boston, MA, USA, 27 June 2016.

43. Buszkiewicz J, Otten J, Tang W et al. (2017) Seattle supermarkets revisited: effect of Seattle's minimum wage ordinance on local area food prices one year following enactment. Presented at AcademyHealth Annual Research Meeting, New Orleans, LA, USA, 26 June 2017.

44. Monteiro CA, Levy RB, Claro RM et al. (2010) A new classification of foods based on the extent and purpose of their processing. Cad Saude Publica 26, 2039-2049.

45. Moubarac J-C, Parra DC, Cannon G et al. (2014) Food classification systems based on food processing: significance and implications for policies and actions: a systematic literature review and assessment. Curr Obes Rep 3, 256-272.

46. Katz LF \& Krueger AB (1992) The effect of the minimum wage on the fast-food industry. ILR Rev 46, 6-21.

47. Matsa D (2011) Competition and product quality in the supermarket industry. QJ Econ 126, 1539-1591.

48. Volpe R (2011) Evaluating the performance of US supermarkets: pricing strategies, competition from hypermarkets, and private labels. J Agric Resour Econ 36, 488-503.

49. Monsivais P, Mclain J \& Drewnowski A (2010) The rising disparity in the price of healthful foods: 2004-2008. Food Policy 35, 514-520.

50. Monsivais P, Aggarwal A \& Drewnowski A (2010) Are socioeconomic disparities in diet quality explained by diet cost? J Epidemiol Community Health 66, 530-535. 